\title{
Redefinición identitaria en migrantes transnacionales: el caso de los exiliados chilenos residentes en Vancouver, Canadá*
}

\author{
Redefinition of identity in Transnational Immigrants: \\ The case of Chilean exiles residentes in Vancouver, Canada
}

Karla Nahuelpan Sánchez ${ }^{* *}$

Facultad de Ciencias Sociales, Universidad Católica de Temuco, Temuco, Chile

Recibido: 19 de abril de 2015. Aprobado: 21 de junio de 2015

\begin{abstract}
Resumen
La dictadura militar en Chile trajo consigo la migración forzada de miles de chilenos, provocando de esta manera la conformación de comunidades transnacionales chilenas en distintos países de acogida. Como efecto de esto se encuentra la redefinición identitaria de los exiliados, ya que al verse obligado a abandonar su país de origen buscan los medios para seguir relacionados con él, tales como la memoria y los símbolos, los cuales entran en contacto en diversos espacios sociales. El objetivo general del artículo es analizar la redefinición identitaria de migrantes transnacionales chilenos residentes en Vancouver, Canadá, en contexto de Dictadura Militar de Chile de 1973-1990. Se entenderá por transnacionalismo la relación que establece un grupo de migrantes con su lugar de origen, en el cual influyen distintos símbolos con los que se sienten identificados y que los orientan a representar su sentido de pertenencia. Siguiendo esta misma línea, identidad será entendida como una construcción subjetiva a través de símbolos y sociabilización, la que puede ir modificándose o readaptándose según las experiencias vividas.
\end{abstract}

Palabras claves: identidad, transnacionalismo, exilio.

\footnotetext{
Este artículo forma parte de la investigación para optar al grado de Licenciada en Antropología, por Universidad Católica de Temuco.

** Antropóloga Social, por la Universidad Católica de Temuco. Correo electrónico: karlanahuelpan@live.com
} 


\begin{abstract}
One of the consequences of the military dictatorship in Chile was the forced migration of thousands of exiles, which resulted in the formation of Chilean communities in different host countries. Forced migration has several effects in the immigrant, being the most significant the identity redefinition. When citizens are forced to leave their country, they seek ways to keep connected with it, this mechanism are memory and symbols, wich come into contact in different social spaces. The overall objective is then to analyze the identity redefinition of Chilean transnational immigrants living in Vancouver, Canada, who were displaced by the military dictatorship of Chile in 1973-1990. We will understand transnationalism as a relationship that establishes a group of immigrants to their place of origin, where the influence of different symbols that they identify will guide them to represent their sense of belonging. Following the same perspective, the pertinent definition of identity for this research is that it is understood as a subjective construction through symbols and socialization, which can be modified or readapted by living situations of the immigrants.
\end{abstract}

Keywords: identity, transnationalism, exile.

\title{
Introducción
}

La migración es entendida como "el abandono por determinadas personas de su lugar de residencia y la adopción de uno nuevo durante un periodo relativamente largo, aunque no sea necesariamente permanente" (Sutcliffe, 1998, p. 13). Esta definición concuerda con la situación vivida por miles de chilenos quienes, durante la dictadura militar llevada a cabo por Augusto Pinochet, se vieron forzados a abandonar su país.

La dictadura militar de Chile, -11 de septiembre de 1973 hasta 1990 tras el plebiscito que se realizó el 5 de octubre de 1988-, trajo consigo consecuencias desde los ámbitos psicológicos y socioculturales para los exiliados políticos que perduran hasta la actualidad. De manera más específica, los efectos psicológicos apuntan directamente a la identidad de aquellas víctimas de la migración forzada y a la de sus hijos, es decir, influyó en la redefinición identitaria de los exiliados chilenos, así también, las consecuencias psicológicas del exilio incluyen la ruptura abrupta de un proyecto de vida; la pérdida de las redes sociales y emocionales tales como la familia, amigos y colegas; la pérdida de 
un paisaje y una geografía familiar; el fin de la participación activa de las personas en la vida cotidiana de su país y, por consiguiente, la pérdida de la historia personal, de la biografía y del sentido de identidad (Domínguez, 1994 en Espinoza y Buchanan-Arvay, 2004). Por otra parte, las consecuencias socioculturales hacen referencia a la opción de formar y mantener una vida transnacional al verse en la obligación de una inserción en dicha ciudad.

Fue una época de tortura, exilio y desaparición de chilenos simpatizantes y militantes de la Unidad Popular, por esto es que los efectos recién mencionados fueron provocados por actos de terrorismo de Estado, entendiendo que este "fue una metodología precisa y sistemática, producto de un plan político para la región que estaba inmersa en procesos y luchas populares de liberación, con el objetivo de destruir y desmantelar todas las estructuras sociales, culturales, civiles y políticas" (Ministerio de Justicia y Derechos Humanos de la Nación de Argentina, 2006, p. 16), entrando así en esta definición el exilio como una forma de Terrorismo de Estado.

Los antecedentes que se manejan en cuanto a la cantidad de exiliados ${ }^{1}$ durante este periodo son variados. Por una parte, según el Informe Rettig (1993), de una población de 10 millones de habitantes al momento del Golpe de Estado, 1,6 millones de personas fueron forzadas a emigrar o buscar refugio, 50.000 fueron detenidos como prisioneros políticos, y 2.920 fueron asesinados o hechas desaparecer. Sin embargo, otros datos indican -con respecto a la cantidad de exiliados- que 400.000 chilenos debieron abandonar el país por razones políticas (Bolzman, 1993; Norambuena, 2000 en Rebolledo, 2012), de los cuales un 3,85\% emigraron a Canadá.

La dictadura militar en Chile produjo una migración forzada masiva hacia distintos países, partiendo en primera instancia a países de América Latina, sobre todo a Argentina, por la cercanía con Chile y la facilidad de poder establecerse en dicho país. Pero, este también se vio afectado por una dictadura militar en 1976 (así como en la mayoría de América del Sur), debido a esto muchos de los exiliados chilenos residentes en Argentina

1 Según la ley $\mathrm{N}^{\circ} 18.994$, la cual crea la Oficina Nacional de Retorno, se entiende por exiliados a: (a) Los condenados por penas privativas de libertad conmutadas por extrañamiento; (b) Expulsados u obligados a abandonar el territorio nacional por resolución administrativa; (c) Quienes, luego de viajar al extranjero, fueron objeto de prohibición de reingresar a Chile; (d) Refugiados en sedes diplomáticas y posteriormente transferidos al extranjero; (e) Quienes en el extranjero se acogieron a la Convención sobre Refugio de Naciones Unidas y obtuvieron refugio de carácter humanitario; (f) Quienes se vieron obligados a abandonar el país, debido a la pérdida de su trabajo por motivos políticos y luego sufrieron prohibición de reingreso; (g) Los hijos, cónyuges y miembros del grupo familiar de exiliados políticos que debieron abandonar el país en programas de reunificación familiar y permanecieron a lo menos tres años ininterrumpidamente en el exterior. 
tuvieron que vivir una segunda migración forzada, en donde muchos decidieron establecerse en países de Europa o América del Norte.

Es así que la opción del 3,85\% de los exiliados decidieron ir a Canadá, país conocido por estar conformado netamente por migrantes, con programas especiales para inmigrantes y refugiados por parte del Departamento de Ciudadanía e Inmigración ( $\mathrm{Ci}$ tizenchip and Immigration) y también por el Ministerio de Bienestar social (Ministry of Social Welfare). Los exiliados chilenos llegaron a Canadá asentándose en ciudades tales como Winnipeg, Montreal, Edmonton, Vancouver, entre otras, siendo la última ciudad mencionada el espacio donde se realizará la investigación. De esta manera, el gobierno canadiense, al aprobar la solicitud de refugio para los exiliados chilenos, los asignaban a distintas ciudades a lo ancho del país. Pasado los tres primeros meses de permanencia en dicha ciudad (en algunos casos seis meses o más) muchos chilenos decidieron trasladarse a la ciudad de Vancouver, donde se les ofrecía una mejor estabilidad económica y social.

En esta, los exiliados chilenos comenzaron a conformar comunidades transnacionales, entendiendo el transnacionalismo como la relación que establece un grupo de migrantes con su lugar de origen, en el cual influyen distintos símbolos con los cuales se sienten identificados y los orientan a representar su sentido de pertenencia; además una forma de cómo los migrantes tienden a vincular su país de origen con el receptor utilizando distintos medios, destacando por sobre ellos la memoria y el sentido de pertenencia (Ribeiro, 2001; Vono de Vilhena, 2006; Velasco, 2009). Claro está que el exilio y migración forzada provocan un proceso diferente de incorporación a una sociedad y cultura distinta (Handlin, 1973 [1951]; Takaki, 1993). Por esta razón, la identidad se ve ligada al país de origen, en este caso Chile, por lo cual la vida de los (trans)migrantes depende de múltiples y constantes interconexiones a través de barreras internacionales geográficas, por lo que sus identidades estarán ahora configuradas en relación a más de un Estadonación (Glick Schiller, Basch y Szanton Blanc, 1995). Lins Ribeiro (2001) afirma que la transnacionalidad "es la relación entre territorio y diferentes arreglos simbólicos y políticos que orientan las maneras en que las personas representan su pertenencia a unidades sociopolíticas y económicas" (pp. 61-62), además que la transnacionalidad mantiene características virtuales y potenciales de los migrantes.

En base a estas definiciones y afirmaciones, queda preguntarse ¿Qué pasó con los exiliados chilenos acabada la dictadura? ¿Permanecen en sus países de acogida o retornaron a Chile? ¿Cuál fue el efecto que todo este proceso tuvo en su identidad y en la formación de la identidad de aquellos nacidos en el exilio? ¿Cómo influye Canadá en la vida transnacional? 
Por otra parte, se entenderá la identidad como una construcción subjetiva a través de símbolos y sociabilización, que puede ir modificándose o readaptándose según situaciones que vivan los migrantes (Hall, 1993; Bauman, 2000; Cuevas, 2008). Es así, como menciona Grimson (2010), la identidad sería una categoría de pertenencia, sentirse parte de algo. Sin embargo, es necesario destacar que no es posible hablar de una sola identidad, sino que de identidades, los cuales son el resultado de intereses y procesos políticos (Grimson, 2010). Pero, como se había mencionado anteriormente, esta definición de identidad tiene una directa incidencia en los efectos que trajo consigo el exilio forzado de los chilenos, provocando de esta manera una redefinición de las identidades de ellos en base a la vida transnacional en Canadá. Por ende, queda preguntarse ¿̇cuál es la identidad chilena de aquellos que siguen viviendo en el exilio? ¿Cómo se (re)construye?

En otras palabras, el transnacionalismo de los exiliados chilenos se puede entender desde la identidad, ya sea esta colectiva o individual ${ }^{2}$, y por otra parte por el sentido de pertenencia por el país de origen, por el sentimiento de arraigo con éste.

Según lo señalado hasta el momento es que se presenta como objetivo general de la investigación el analizar la redefinición identitaria de migrantes transnacionales chilenos residentes en Vancouver, Canadá, en contexto de dictadura militar de Chile de 1973 - 1990. Para dar respuesta a esto es que se guiará por los siguientes objetivos específicos: (1) identificar cómo los migrantes redefinen su identidad bajo la condición de la transnacionalidad; (2) vincular el sentido de pertenencia y la redefinición identitaria en la formación de la comunidad transnacional chilena; y (3) comparar las percepciones que se tiene de identidad para los transmigrantes y para los retornados políticos. Dado estos objetivos cabe mencionar que la redefinición identitaria, tal como lo considera OdgersOrtiz (2005), implica el abandonar un contexto e instalarse en uno nuevo, en este caso sería a través de la migración forzada de los chilenos simpatizantes con la unidad popular, quienes llegaban a diversos países de acogida, los cuales serían este nuevo contexto. Siguiendo con la misma autora, el proceso de redefinición identitaria implica además la negociación de la relación con los otros y la consecuente delimitación del lugar que el individuo podrá ocupar en una y otra sociedad de referencia (2005, p. 101).

La metodología implementada es cualitativa, utilizando el método de la etnografía tanto en Chile como en Canadá, en donde se realizaron entrevistas en profundidad a tres

2 Es importante destacar la diferenciación específica para este artículo sobre la identidad individual y colectiva, en donde la primera conlleva a la segunda, es decir, el sentirse parte (en este caso) de Chile, lleva al querer representarlo a través de la comunidad transnacional, siendo de esta manera cómo se genera la identidad colectiva. 
familias retornadas a Chile y tres familias pertenecientes a la comunidad transnacional en Vancouver (unos 15 sujetos aproximadamente). Cabe destacar que se consideraron primordialmente dos generaciones, que van desde los 50 hasta los 80 años aproximadamente, sin embargo, también se consideró la opinión y vivencias de una tercera generación, que iría desde los 20 hasta los 35 años de edad aproximadamente. Las familias seleccionadas (sobre todo las que aún permanecen en Canadá) fueron todos exiliados políticos, cabe destacar esto ya que en la comunidad chilena de Vancouver hay muchos quienes llegaron por otros motivos a la ciudad, por lo cual se fue bastante cuidadoso para selección de las familias. Dentro de estas familias se encuentran presentes militantes del Partido Comunista, pertenecientes al Movimiento de Izquierda Revolucionaria MIR, ferroviarios, músicos, dueñas de casa y estudiantes. Dicha investigación tuvo una duración de aproximadamente un año.

Dado esto es que el artículo se compone de cinco partes. En la primera (conformación de la comunidad chilena en Vancouver), se expone el proceso de llegada de los exiliados chilenos y cómo comenzaron a conformarse las comunidades transnacionales. La segunda (el transnacionalismo chileno vivido en Vancouver: espacios y redes transfronterizas) habla sobre los mecanismos que utilizan los chilenos transmigrantes para mantener las redes con sus compatriotas, tanto dentro de Vancouver como las redes transfronterizas con Chile. La tercera (el retorno) habla sobre el proceso de retornar al país durante la dictadura y luego de terminada esta, la reinserción sociocultural e identitaria para exiliados y cuál ha sido su resultado hasta la actualidad. La cuarta (lugar, símbolo y sentido transnacional) es un análisis respecto a la actualidad de la comunidad transnacional chilena de Vancouver, donde se identifican los distintos símbolos que adquieren un sentido de pertenencia y de arraigo con Chile, los cuales utilizan para mantener su relación con el país. Por último, se finalizará el artículo con algunas reflexiones con las que se pretende entrelazar todos los aspectos que dan vida a una comunidad transnacional, así también se pretende dejar abierto el diálogo no tan solo al transnacionalismo en sí, sino también a cómo los contextos políticos-sociales afectan e interfieren en la construcción de identidad y su importancia en los estudios sociales.

\section{Conformación de la comunidad chilena en Vancouver}

La inserción al país era lenta y a la vez dolorosa, un proceso muy difícil para quienes fueron despojados de su país. Es de esta manera que en este proceso de inserción se pueden categorizar tres tipos de reacciones por parte de los exiliados chilenos: la primera 
era olvidarse de Chile e insertarse por completo a la sociedad canadiense. Esto implicaba el alejamiento de la comunidad chilena y buscar sistemas de financiamiento para realizar estudios superiores, siempre con la idea de permanecer en Canadá y formar una familia en dicho país. Sin duda en los primeros años de exilio esta postura era la que menos simpatizantes tenía, pero de igual modo hay quienes optaron por esta. De alguna manera, esto influyó que en un principio la comunidad chilena en Vancouver no contara con una organización de base consolidada, provocando más bien, la dispersión de los chilenos alrededor de la ciudad. Cabe destacar en este sentido la importancia -tanto de la sociedad como del gobierno canadiense- para la inserción laboral, social, educacional, económica, etc., para con los refugiados chilenos, ya que con la ayuda de diversos programas de inserción creadas por el Departamento de Ciudadanía e Inmigración y el Ministerio de Bienestar Social, desde el momento en que se ingresa al país (como refugiados), se comienzan a aplicar estas leyes y programas de inserción. Se les asigna una ciudad para que puedan comenzar a laborar (ciudad elegida según las necesidades del país), se les hace entrega de una casa, departamento o pieza para vivir temporalmente (según la cantidad de integrantes), se les ofrece clases de inglés para una mejor inserción social, etc. Es importante mencionar en este sentido que la mayoría de esta categoría eran refugiados jóvenes que llegaron solos a Canadá y que, en algunos casos, habían comenzado estudios superiores en Chile y quisieron continuarlas durante el exilio.

La segunda es una postura de militancia política por parte de los refugiados. Esta categoría hace directa referencia a quienes ya eran activistas y/o militantes políticos en Chile o a quienes decidieron serlo después del exilio, con el objetivo final del retorno de la democracia en Chile. Como es posible suponer, muchos de los exiliados eran pertenecientes al Partido Comunista o al MIR, por lo cual optaban por esta postura, aunque -como menciona una de las entrevistadas- "tú no necesitabas ser militante de un partido para mostrar tu compromiso con el Gobierno, con el sistema que se vivía el 70 o 73". Pero, de todos modos, muchos de ellos volvieron a Chile para pertenecer al FPMR (Frente Patriótico Manuel Rodríguez), volviendo incluso con niños para integrarse a la resistencia, tal como cuenta Carmen Aguirre en su libro (2011), hija de una revolucionaria chilena, quien volvió para participar de la resistencia acompañando a su madre y a su hermana cuando tan solo eran niñas. Además, muchos de los pertenecientes al Partido Comunista eran becados para realizar estudios superiores en la URSS y terminando aquello, volvían a militar a sus partidos en Chile.

Por último, la tercera categorización, era vivir una vida de transnacionalismo, la cual implicaba establecer redes de contacto con chilenos quienes se encontraban en su misma situación y a la vez generar redes transfronterizas con el país de origen (Chile). En 
esta última categoría destacan las familias de refugiados en Canadá, todos siempre con la mentalidad de volver a su país, también aquellos que fueron exiliados sin sus familias y optaban por una vida transnacional aspirando de esta manera a una pronta reunificación familiar.

Así, como menciona Glick Schiller, Basch y Szanton Blanc (1995), los transmigrantes son inmigrantes para quienes su vida diaria depende de múltiples y constantes interconexiones a través de fronteras internacionales y de los cuales su identidad colectiva está configurada en relación a más de un Estado-nación. De este modo, con la llegada de los exiliados chilenos a Canadá, su identidad estaba configurada en relación a Chile, lo cual los llevó a conformar su propia comunidad para mantener sus costumbres identitarias. Sin embargo, con el retorno de la democracia, muchos decidieron quedarse en Canadá -o incluso después de retornar a Chile volvieron para vivir nuevamente a Canadá- en donde permanecían aún en esta comunidad chilena, lo que provocó que su identidad colectiva ahora estuviera configurada en relación a dos Estados-nación, de la cual se sentían identificados (Chile) y a la cual tenían que insertarse (Canadá). Es por esta razón que resalta la importancia e influencia que tuvo Canadá como país y sociedad para que los refugiados chilenos configuraran su identidad. Ya que las leyes sociales, laborales, etc., que posee este país para con los inmigrantes-refugiados, permiten generar un lazo también sentimental con este nuevo Estado-nación. Pero, sin embargo, lo que más destaca es el hecho de ser un país multicultural, lo cual permite el mantener viva las costumbres y tradiciones de cada ciudadano residente en Canadá.

En esta última categoría, cabe destacar además el transnacionalismo generacional. Por lo general, el tipo de exilio que destacaba para los que llegaban a Canadá era de un exilio familiar, contando de una a dos generaciones. Igualmente, hubieron muchos quienes en su país de acogida formaron sus propias familias, habiendo niños nacidos durante el exilio de sus padres, lo cual transformaba a Canadá en su país de origen y a Chile se le veía como un país lejano, de donde venían sus padres y abuelos, pero con el cual con el paso del tiempo (y también porque sus padres y abuelos mantuvieron relaciones sociales con chilenos) fueron creando un lazo emocional con Chile, por lo cual ahora su identidad (en la mayoría de los casos) está configurada con vínculo en los dos Estado-nación.

Es así, como estas tres categorizaciones tienen una relevancia para los estudios sociales contemporáneos. Sin embargo, es esta última categorización -la del transnacionalismo- en la cual se generan muchas veces más interrogantes que respuestas al verse involucrados otras condiciones que dan vida a esta categorización, estas serían el exilio, la identidad, la memoria, el lugar (espacio), los símbolos, la globalización, sentido de per- 
tenencia, desarraigo, redes transfronterizas, entre otros que permiten un análisis desde la antropología contemporánea para este tipo de procesos de migraciones forzadas y la conformación de comunidades transnacionales.

Dado todos los aspectos recién mencionados es que se comenzó a conformar en 1981 una Cooperativa de Vivienda -que en un principio estaba destinado a los residentes chilenos quienes vivían en Vancouver-, para mantener vivos estos lazos fronterizos y transfronterizos. Es así que la comunidad chilena -y muchos grupos de otros migrantes quienes llegaron a la misma ciudad- fueron postulando a espacios para poder conformar sus propias cooperativas de vivienda. Estas cooperativas de vivienda tienen como objetivo social el proporcionar viviendas, locales y otros inmuebles a un grupo social determinado.

La cooperativa en un principio estaba conformada por alrededor de 30 familias de chilenos exiliados, quienes en su intento de sobrellevar su estadía en el país buscaban relacionarse entre ellos para así poder mantener sus costumbres. La conformación de esta Cooperativa consistía en la compra -por parte del gobierno canadiense- de un terreno para la construcción de los hogares y una sala en común en donde se realizaban diversas actividades. Desde siempre ha existido una directiva, la que organizaba los eventos, las reuniones y también la toma de decisiones respecto a la comunidad y convivencia dentro de la Cooperativa, además de seleccionar a las familias que llegaban a vivir a dicho lugar, siempre respetando de manera esencial las elecciones democráticas llevadas a cabo en dichas reuniones, en donde cada habitante de la Cooperativa tenía (y tiene aún) voz y voto. Sin embargo, actualmente, aunque en su mayoría siguen siendo chilenos, no son más de ocho familias chilenas originales las que permanecen y, además, se está conformada por otros residentes latinoamericanos y también canadienses.

Dentro de las actividades que se realizaban/realizan se encuentran las reuniones semanales, tales como partidos de futbol, ferias, asados, peñas, misas a la chilena, actividades en conmemoración del 11 de septiembre, las celebraciones de las fiestas patrias, reuniones con el consulado chileno, entre otras actividades. De esta manera se comenzaban a establecer fuertes lazos sentimentales entre los chilenos en el exilio, generándose una especie de apoyo moral y sentimental por la situación vivida por muchos compatriotas.

Las fiestas patrias también eran conmemoradas con peñas. Incluso en la actualidad, existe una panadería llamada "Panadería Latina", donde los dueños son chilenos, y es un lugar de encuentro para todos los chilenos y latinos residentes en Vancouver. En dicha panadería se prepara (especialmente para esta fecha de celebración) comidas 
consideradas típicas chilenas, tales como empanadas, sopaipillas, choripan, pastel de choclo, humitas, bebestibles tales como el mote con huesillo, etc. Una reunión que se realiza al aire libre para todos aquellos que quieran asistir, con música en vivo, música folclórica chilena, en donde las cuecas se hacen presente, lo cual daba pie a que un gran número de personas comenzaran a bailarla, algunos de ellos vestidos con el traje típico del huaso chileno. Pero la celebración no quedaba solo para chilenos, es acá donde sale a luz el aspecto multicultural que ha tomado la organización chilena en Vancouver, es así que se daba paso a la celebración de las naciones latinoamericanas, ya que además llegaban distintas agrupaciones artísticas para participar de esta celebración, con bailes típicos de Perú, Ecuador, Bolivia, entre otros. En otras palabras, el 18 de septiembre no es tan solo para celebrar a Chile, si no que a la unidad latinoamericana existente en dicha ciudad (Cuaderno de Campo, 20 de septiembre de 2014).

Es muy importante destacar que no todos los chilenos que residen en Vancouver pertenecen a esta Cooperativa, más bien están dispersos por toda la ciudad, pero sin embargo se mantienen los lazos establecidos entre ellos y además las redes transfronterizas con Chile. Es así que la Cooperativa de los chilenos ha podido mantener estos lazos, realizando las diversas actividades antes descritas, en donde se invita a toda la comunidad chilena a participar.

\section{El transnacionalismo chileno vivido en Vancouver: espacios y redes transfronterizas}

La cooperativa es la que permite recrear las costumbres y tradiciones que estos migrantes sienten los representan como chilenos, en otras palabras, ellos buscan estos medios para representar su identidad, para recordar el Chile que dejaron.

De este modo, la migración forzada en contexto de dictadura militar genera las diversas reacciones por parte de los migrantes, quienes van a definir el cómo van a ir reconstruyendo y redefiniendo su identidad de chilenos, las cuales era: 1) el olvidarse de Chile e insertarse por completo a la sociedad canadiense; 2) el convertirse en un activista político, por lo tanto optar por una postura militante; y 3) la opción de una vida transnacional. En esta última se puede identificar la categoría de identidad -que llamaré esencialista- por parte de los refugiados chilenos, quienes buscan a toda costa reproducir sus costumbres y tradiciones en una nación ajena de la que luego también configurarán su identidad. 
Por identidad esencialista se va a entender como aquella que busca recrear y mantener su identidad del país de origen, del país que recuerdan haber dejado, en cuanto a sus relaciones sociales, el diario vivir, las costumbres y tradiciones, etc., y reproducirlo en el país ajeno en donde se encuentran.

Es esta identidad esencialista la que da pie al transnacionalismo, que se comenzaba a vivir incluso antes siquiera de nacer la Cooperativa de chilenos. Con reuniones durante los fines de semanas en una casa que habilitaron los mismos refugiados, a la que nombraron Casa de la Cultura, en donde se realizaban las actividades antes mencionadas y además donde se programaban reuniones para los miembros de partidos políticos, como el partido comunista, el partido socialista y miristas. La casa también tenía una pieza que fue habilitada como una biblioteca, en donde se encontraban diarios de tendencia marxista con noticias de Chile, música con contenidos sociales (lo que más se nombra son de Inti Illimani, Illapu, Quilapayún, Víctor Jara), etc., estos lugares son los que se pueden denominar como los espacios sociales transnacionales (Santana, 2010).

....recuerdo que en Canadá uno andaba buscando el folclore, andaba buscando todo lo que te pueda ayudar a sentirte más cerca de tu país... yo me fui en el 80, o sea, hace siete años que yo no escuchaba nada de eso, entonces escuchar a Víctor Jara era como algo tan melancólico porque te llevaba inmediatamente a una época de la vida que tu vivías y recordabas.

Importante es destacar que a pesar de que exista esta cooperativa de chilenos existen muchos de ellos quienes se han "independizado" de esta comunidad y que han decidido insertase de manera autónoma a la sociedad canadiense, pero sin dejar de lado sus "costumbres" chilenas. A pesar de pertenecer ahora a una sociedad y cultura muy diferente a la que vivieron en Chile, mantienen su lengua, su ideología, el compartir en familia, etc. Mucho se ha hablado de que en países de Norteamérica las relaciones sociales y familiares tienden a ser más frías de lo que uno acostumbra en Chile y en Latinoamérica en general, por lo cual es importante destacar que a pesar de los años permanecidos en Canadá este aspecto no ha sufrido un mayor cambio y que las relaciones interpersonales siguen teniendo un significado esencial en el diario vivir y en las identidades de los chilenos,

...nosotros cuando llegamos a Canadá éramos mi señora y mis hijos, después acá ellos se casaron y tuvieron sus familias, no valía la pena volvernos a Chile... nunca vivimos en la cooperativa pero desde su inicio siempre estuvimos involucrados, para las fiestas patrias vamos a celebrar allá, pero el resto del año lo pasamos solamente con la familia, 
nos juntamos dos veces a la semana, hacemos asaditos, nuestros nietos nacidos acá hablan un perfecto español, siempre estamos al tanto de lo que pasa en Chile, vemos las telenovelas, las noticias, etc., estamos más al tanto de lo que pasa allá de lo que pasa acá.

Es así que el transnacionalismo no es algo que se vive tan solo en el país de acogida, ya que es necesario que existan redes transfronterizas, un nexo constante con el país de origen del migrante. Muchos exiliados tuvieron que abandonar el país junto a toda su familia, pero también hay quienes salieron solos, dejando en Chile a hijos, padres, hermanos, etc. Por lo tanto, la constante relación entre el país de origen y de residencia conlleva a que las comunidades de transmigrantes reproduzcan sus costumbres en el país de acogida, la que permite constantes y múltiples conexiones de carácter sentimental, los cuales establecen un sentido identitario con el país, sentimiento que quizás antes no era relevante, pero que luego de una migración forzada este se torna fundamental en la construcción de la identidad transnacional. En este caso, para aquellos que llegaron a Canadá fue el reafirmar el sentirse identificados con el ser chilenos, por lo cual quisieron formar y mantener una vida transnacional. De aquí se puede identificar la categoría de "transnacionalismo afirmativo", ya que se busca el mantener viva la cultura, tradición, sociedad chilena y representarla en Vancouver, esta categoría de transnacionalismo directamente relacionado con la identidad esencialista.

Es así que cuando se habla de estas redes transfronterizas se habla -durante la dictadura- del envío de cartas a familiares en el país, las llamadas telefónicas (aunque ocasionales y muy precisas por el costo que tenía en ese entonces) y, actualmente, los envíos de correos electrónicos, la transferencia de dineros de un país a otro, la facilidad con la que se permite viajar, etc. En la actualidad, además, es más accesible la transferencia de información y de ideas de un país a otro, lo cual además ha facilitado el sentirse más cerca del país de origen estando en otro y, por ende, ha permitido que el sentimiento de arraigo con Chile no haya disminuido, sino que se ha mantenido y en algunos casos incluso ha aumentado.

Yo tenía 15 años cuando me fui a Canadá, con mis papás y mis hermanos, después de unos años me casé allá (con un chileno) y al tiempo mi familia comenzó a volverse a Chile, yo me quedé con mi marido y empezamos a formar una familia, pero siempre con la intención de volvernos terminada la dictadura. Mis suegros al poco tiempo también se volvieron a Chile, entonces la gente de la cooperativa era nuestra familia, no vivíamos ahí pero siempre compartíamos con ellos. Desde Canadá no podíamos llamar a mis papás porque no tenían teléfono, así que nos teníamos que poner de 
acuerdo para que estuvieran en la casa de algún tío para llamarlos ahí, para el nacimiento de mis hijos se les avisó por telegrama, las cartas se demoraban meses en llegar. No quisimos estar más tiempo lejos de la familia, así que nos volvimos a Chile con nuestros tres hijos en 1995.

El relato recién citado evidencia cómo en la actualidad la tecnología ${ }^{3}$ ha jugado un papel primordial para la vida transnacional. Además, se destaca que muchos de los exiliados llegaron o están llegando a una edad en que la nostalgia por su país y por su familia está primando por sobre la estabilidad económica y social que han conseguido en su país de acogida, teniendo el deseo de volver a su hogar, pero sin abandonar a la familia que han formado en su país de acogida. Es así que muchos han optado por permanecer en su país de acogida, siendo de esta manera que se confirma el aporte que la tecnología ha hecho para mantener los lazos con el país de origen, por lo cual "esta migración fundada en las redes sociales, tiene un carácter recurrente y oscilatorio manteniendo fuertes vínculos, materiales y simbólicos, entre los lugares de origen y los de destino. Por este motivo, desarrolla infraestructuras, instituciones y formas culturales propias" (Tavernelli, 2011, p. 11). Es decir, el transnacionalismo se piensa y se vive desde la acción, "desde los sujetos sobre el espacio geográfico -configurando un espacio transnacional-; y desde los espacios conformados como territorios donde ellos mismos "sirven a las acciones, prácticas y representaciones de los migrantes" (Sassone, 2008, en Tavernelli 2011). Es así que el concepto espacio comienza a tener una relevancia primordial en el estudio del transnacionalismo, ya que es el lugar geográfico en que se lleva a cabo. Esto no hace solo referencia a los dos países involucrados, sino también (en este caso) a la Cooperativa de chilenos, a la Casa de la Cultura, la Panadería Latina, negocios donde concurrían/concurren, etc.

Es importante destacar en este sentido que el país receptor actúa además como un ente integrador para conformar y mantener una vida transnacional. Por lo tanto, los espacios en donde conforman las acciones transnacionales comienzan a ser espacios con sentido de pertenencia, ya que es un espacio que representa su país de origen. Ya se había hablado de que Canadá, por tener políticas multiculturalistas, permite el poder mantener vivas las costumbres y tradiciones de los inmigrantes que residen ahí. Ofrece diversas ayudas sociales en cuanto la inserción y además políticas laborales en contra de la discriminación étnica-racial, por lo cual el factor de ser un inmigrante en dicho país no significa el tener menos posibilidades de acceder a un empleo.

3 En un sistema de vida transnacional permite, de diversas maneras, poder establecer estas redes transfronterizas entre el país de origen y el de residencia. Por ejemplo, durante la dictadura, era a través del envío de cartas, telegramas y llamadas telefónicas ocasionales. Actualmente, a éstas, se le suman además el internet, las redes sociales de éstas, las videoconferencias, etc. 
Así, Canadá como país receptor se transforma en el país que les abrió las puertas a los refugiados, que los acogió, a diferencia de Chile, del cual fueron despojados a la fuerza por tener una ideología política distinta. Y es así que vuelve aparecer la categoría de identidad esencialista, ya que se busca representar su identidad chilena que recordaban antes de la dictadura, lo cual conlleva a la categoría de transnacionalismo afirmativo de la(s) identidad(es) chilena.

Es así que hay diversas condiciones que permiten la transnacionalidad. En primer lugar, se puede encontrar el motivo de la migración -ya que esta puede ser forzada o voluntaria-, pero por lo general, serán a través de las migraciones forzosas que los migrantes buscan la manera de seguir estableciendo sus lazos sentimentales con su país de origen. En segundo lugar, están las redes transfronterizas (apoyadas además por la globalización), las cuales han jugado y juegan un rol fundamental en la vida transnacional, ya que son las que permiten el contacto permanente con el país de origen. En este sentido -durante la dictadura-, eran las llamadas telefónicas y el envío de cartas las que mantenían estos lazos con los familiares que quedaron en Chile o que incluso fueron exiliados (o refugiados) en otros países. Actualmente, la digitalidad ha agilizado -y reforzado- estas redes, en donde las llamadas telefónicas son más accesibles que en los años 70 u 80 , en donde ya no es necesario el envío de cartas y éstas son reemplazadas por correos electrónicos, en donde el envío de encomiendas son bastante más rápidas y accesibles, etc. El concepto de red permite este fenómeno de la transnacionalidad, ya que por los vínculos, lazos, que se generan no tan solo a nivel transnacional, de un país a otro, sino que también por las redes sociales, sentimentales, etc., dentro del mismo país y/o ciudad en la que se está actualmente, permite de esta manera poder sobrellevar mejor la estadía en el país de acogida. Así, una tercera condición que da pie para una vida transnacional es el espacio, éste hace referencia directamente a los espacios sociales transnacionales que permiten estas interacciones, tanto los países involucrados como -en este caso- la Cooperativa de Chilenos, la Casa de la Cultura que habilitaron con ese mismo propósito, las iglesias en donde se realizaban las misas a la chilena, etc. Son estos aspectos los que permiten ir configurando la identidad en base a estos dos Estados-naciones.

\section{El retorno}

Desde antes de terminada la dictadura militar ya se llevaban a cabo los retornos a Chile por diversas razones. Los principales motivos del retorno de los exiliados tienen que ver con la reunificación familiar y el sentimiento de desarraigo. Como se ha mencio- 
nado anteriormente, hay muchos quienes militaban en partidos políticos, por lo que su identidad política los llevó a retornar al país para luchar por la vuelta de la democracia. Hay otros quienes salieron solos desde Chile, por lo cual uno de los principales factores para volver al país, aun estando en dictadura militar, era la familia. Por último, estaban aquellos quienes nunca se acostumbraron al sistema de vida llevado en Canadá, por lo cual optaron por el retorno a Chile, intentando de esta manera rehacer sus vidas en su país de origen. Terminada la dictadura, se llevó a cabo un retorno masivo por parte de los exiliados chilenos, aunque este iba siendo paulatino de acuerdo con lo que se observaba que iba ocurriendo en el país.

Sin embargo, estas personas se vieron enfrentadas a una realidad completamente distinta al llegar nuevamente a Chile, tanto en lo político, económico, social, cultural, etc. Se menciona mucho por parte de quienes aún viven en los países de acogida y también por parte de los retornados, que en Chile aún está el miedo por lo que ocurrió. Los principales afectados (quienes ahora tienen entre 40 y 80 años aproximadamente) mencionan que el proceso de cambio que sufrió el país provocó un cambio también de mentalidad, en el sentido de la individualidad de las personas, el miedo constante a lo que es la represión política (que lo asocian con la represión policial o militar) y además el sistema de vida, tanto en su economía como en su nueva política neoliberal.

Debido a estas situaciones (el exilio, la vida transnacional y el retorno) es que se va reconfigurando las identidades individuales y colectivas, creando un individualismo aún mayor de lo que había anteriormente. A modo de ejemplo, como menciona una de las entrevistadas...

Me acuerdo que en la Unidad Popular había un programa que se llamaba 'Póngale el Hombro' y eran trabajos tan lindos que se hacían. Yo era chica, no me acuerdo tan claro, pero se me ocurre que eran así como las juntas de vecinos. Por ejemplo, decían que este fin de semana vamos a ponernos a hacer una plaza con juegos y los vecinos trabajaban, o sea no como hoy día, que hay vecinos que tu no los ves en toda una semana o a veces no te saludan, era otra la convivencia que existía con la gente, otro compromiso, cómo se querían conseguir y hacer las cosas, todo el mundo cooperaba.

Muchos mencionan que el retorno al país fue igual de difícil emocionalmente que el exilio mismo, ya que se llegó a un país que no prestaba ningún tipo de ayuda (o una de mala calidad) por parte del Estado, lo cual hizo que se volvieran a sentir "desilusionados" del país, y esta desilusión lo asociaban directamente con el sentirse identificados o no con el ser chileno, lo que pone en tela de juicio la identidad. 
...uno se acostumbró al sistema de vida en Canadá. Llegando a Chile el único beneficio que teníamos era Prais ${ }^{4}$, que es un programa de salud ligado a Fonasa, pero imagínate, en todo el sector sur de la región (Araucanía) hay un solo doctor para atender a más de mil pacientes, se demoran hasta dos años a veces para darte hora con un especialista. Fue muy brusco el cambio de Canadá a Chile...

Queda en evidencia que la reinserción a Chile fue y ha sido un proceso difícil de sobrellevar por los retornados, influenciando de esta manera aún más en la reconstrucción y redefinición identitaria de ellos. Los grandes cambios sociales, económicos, políticos y, por supuesto, culturales que sufrió el país implicó un no reconocimiento de la patria que se había dejado, del cual habían sido despojados, esto también debido por la cantidad de años que se permaneció fuera de la patria (desde 10 a 20 años aproximadamente). Al hablar con retornados políticos, o con aquellos que siguen viviendo en su país de acogida, es muy típico escuchar que "Chile no es el mismo país que dejamos". Ellos recuerdan la época de la Unidad Popular, de movilizaciones sociales, de una sociedad más comunitaria, etc., sin embargo, en la actualidad, se encuentran con una sociedad individualizada y atemorizada, no empoderada ni social ni políticamente, donde se sigue inserto en el miedo heredado de la dictadura. Es acá en donde se pone en tela de juicio la identidad esencialista, la cual era la que representaba en su mayoría a los refugiados chilenos residentes en Vancouver.

Ya se había mencionado que la vida en el exilio fue muy difícil y que trajo -entre otras tantas consecuencias- muchos divorcios y separaciones familiares. El retorno al país se veía como la oportunidad de la reunificación familiar, de un nuevo comienzo. Para muchos resultó de manera positiva y pudieron sacar provecho de haber vivido en el exilio. Algunos realizaron estudios de educación superior, lo cual les permitió postular a buenos empleos en Chile. Para otros tantos, el retorno no fue tan bueno y (al contrario de lo que pasó con el exilio), este proceso fue el que produjo muchas separaciones familiares, no tan solo divorcios, sino que también hijos (nacidos en el exilio) que nunca se acostumbraron a la vida en Chile, por lo cual decidieron volver solos a su país de origen (en este caso Canadá, pero siendo el caso de muchos otros países también). Estas personas nacidas en el exilio de sus padres, aunque se identifiquen principalmente con su país de origen, igualmente lo hacen con el país de origen de sus padres, resignificando ellos a su manera la identidad chilena dentro de la sociedad canadiense. Así también, existen aquellos nacidos en el exilio quienes por su propia cuenta migraban a Chile para conocer y vivir las raíces de su familia, conocer el país del cuál provenían sus padres. Dado esto,

4 Programa de Reparación y Atención Integral en Salud y Derechos Humanos, entregada por el Estado chileno. 
se puede categorizar un tipo de transnacionalismo, al que ya se había mencionado, el generacional, en el cual el fondo y objetivo no cambia, ya que de igual manera se busca representar la(s) identidad(es) chilena en Canadá, pero son las distintas vivencias y perspectivas las que afectan. Siendo un claro ejemplo el retornar a Chile, el cual trae como consecuencia el llamado "Exilio de los Hijos", generando de esta manera un quiebre entre las relaciones familiares, sociales y, por supuesto, un quiebre en la identidad.

Por otra parte, además del transnacionalismo generacional y el transnacionalismo afirmativo, ahora entra en juego el transnacionalismo por oposición, ya que al "retornar" esta vez al país de acogida, se busca representar lo opuesto que se vivió en Chile al momento del retorno, el seguir con una identidad esencialista de lo que se creía que es la cultura chilena, lo que se recordaba de ella y no en lo que se transformó postdictadura, de aquí es donde se habla de vivir en el pasado, el no asumir que el Chile de antes de la dictadura ya no está, sino que fue reemplazado por uno con políticas neoliberales.

Así, se puede observar que el proceso de (re)construcción de identidad(es) es permanente, que involucra -en este caso- no tan solo el exilio, sino que también el retorno y el llamado exilio de los hijos, quienes igualmente vivieron un proceso de separación de su país de origen. Y son estos mismos procesos los que van generando distintos quiebres en la identidad, ya que ahora la reconstrucción y redefinición identitaria no va a depender tan solo del exilio y la vida transnacional, sino que ahora se suma el retorno, reinserción social, exilio de los hijos y también el retorno al país de acogida para optar por una vida transnacional en vez de estar en su país de origen.

\section{Lugar, símbolo y sentido transnacional}

Como menciona Loreto Rebolledo (2012), los desplazamientos de población suelen ir acompañados de cargas emocionales, y esto sin duda es el caso de los exiliados chilenos.

Hay ciertas costumbres y símbolos en nuestro país que demuestran la chilenidad, el bailar cueca para las fiestas patrias, la Parada Militar, la bandera como símbolo nacional, el copihue, el Escudo Nacional, etc., todos ellos aprendidos desde pequeños. Sin embargo, la carga emocional de estos símbolos va a depender netamente de la construcción que hemos formado en torno a ellos y esto a su vez también va a depender de 
las experiencias de vida de cada uno y de las subjetividades de los individuos. Hay para algunos quienes la parada militar representa el "Día de las Glorias del Ejército de Chile", un día de celebración ${ }^{5}$. Sin embargo, hay otros, como por ejemplo afectados por la dictadura militar, que representa para ellos un día o un acto de tristeza o incluso impotencia. El caso de los exiliados no es muy lejano a esta realidad, es un recordatorio permanente del estar lejos de la patria, de la desterritorialización.

Lo transnacional produce un sentido de pertenencia a un territorio aun estando lejos de él, por lo cual se buscan las maneras de seguir relacionado emocionalmente. Según esto, la memoria funciona como uno de los mecanismos para representar, a través de símbolos, a Chile. Así, el símbolo

es el signo que une dos cosas, dos elementos o dos dimensiones (...) Tiene dos partes. Una es conocida, nos pertenece; es con la que iremos en busca de la otra, con la cual y sólo con la cual se cumple la simbolización. (Beuchot, 2005, p. 76).

Sabido es que Chile posee diversas identidades, producto de las características etno-geográficas del país. Así, muchos asocian la zona nortina con la Fiesta de la Tirana, en la zona central con el huaso chileno, en la zona sur con el chilote y así muchas otras categorías de identificación de lo que es la cultura chilena ${ }^{6}$. Sin embargo, la identidad es -como ya se ha mencionado- una construcción intersubjetiva que puede ir modificándose o readaptándose según las experiencias de vida y, al ser forzado a migrar a un país que no es el propio, influye en esta construcción, tal como menciona Moraes "el contexto de recepción influye en la construcción" (2007, p. 190).

La identidad va de la mano con el sentimiento hacia un lugar, pero a la vez con la memoria y el sentido de pertenencia. Un claro ejemplo de esto son aquellos chilenos que siguen viviendo en sus países de acogida, ya que muchos intentaron volver y establecerse en su país, pero al llegar de vuelta no se sintieron pertenecientes al lugar, como muchos decían "no es el país que dejamos".

5 Cabe destacar que la comunidad chilena en Vancouver no es un grupo homogéneo, en ella hay presente obreros, militantes políticos, ferroviarios, representantes de distintas etnias (tales como la mapuche y aymara, entre otras). Sin embargo, esta investigación se basa en la entrevista a seis familias escogidas aleatoriamente (tres en Chile y tres en Canadá), por lo cual el análisis es en base a ellas y llevadas a una generalización, no representa a la totalidad de la cooperativa.

6 Estas sin duda están siendo categorías generalizadas de lo que podría considerarse "chileno", pero cabe destacar en este sentido que no es lo que representa al país en su totalidad, son quizás las características más visibles y conocidas de nuestro país, pero la diversidad de éste es mucho más, ya que cabe destacar además las diversas culturas presentes en él. 
Cuando se comparan las percepciones de identidad de los transmigrantes chilenos en Vancouver y los retornados políticos, existe una clara diferenciación. Los transmigrantes se sienten identificados con el ser chilenos, justificando de esa manera las costumbres consideradas chilenas que mantienen vivas. Algunos de estos transmigrantes han viviendo 30 años aproximadamente fuera de Chile y no han aprendido el idioma de su país de acogida, pendientes tan solo de los acontecimientos ocurridos en Chile y no del lugar donde viven, etc. Es así que muchos integrantes de la Cooperativa se informan durante todo el día a través del Canal Nacional de Chile, en donde se enteran de los aconteceres de dicho país, disfrutan de las telenovelas y programas de entretención, las cuales son después comentadas entre ellos, la música escuchada por ellos en sus respectivos hogares son por lo general música latinoamericana, incluso tienen un programa radial especial para aquellos latinoamericanos viviendo en Vancouver.

Sin embargo, quienes aún permanecen en su país de acogida afirman que el motivo por el cual no retornaron a Chile (o no lo harán) es debido a que muchos de ellos comenzaron a conformar sus propias familias en Vancouver, a tener hijos, por lo cual no querían despojarlos desde su lugar de origen como ocurrió con ellos. Hay quienes, por otra parte, intentaron volver al país -o que incluso vivieron algunos años de vuelta-, pero el choque cultural y social fui inmenso. Cabe destacar que éstos últimos volvieron a su país de acogida con un sentimiento de derrota por el hecho de no poder haber permanecido en su país, por lo cual quisieron seguir viviendo una vida transnacional. $Y$ es acá donde claramente ve reflejado lo que se mencionaba anteriormente con respecto al transnacionalismo afirmativo y al transnacionalismo por oposición.

En este último motivo mencionado, la memoria juega un rol fundamental, en donde se toman los aspectos más significativos de la identidad chilena para representarlos simbólicamente en un lugar distinto.

Dado esto, queda preguntarse ¿Cómo funciona la memoria? ¿Cómo se nutre ésta de los símbolos? ¿Qué toman de Canadá y cómo lo incorporan a su identidad de origen? Para esto, primeramente hay que entender a la memoria como la práctica social de "traer el pasado al presente" (Ramos, 2011, p. 132), es además "una evocación bajo diferentes formas (pensamientos, sensaciones, imágenes, emociones) que lo redefinen, transforman y resignifican, pero al mismo tiempo, se enmarca en nuestra identidad y en la visión que tenemos de lo que somos y pensamos" (Lira, 2010, p. 9). En segundo lugar, cabe categorizar -en este caso- a la memoria chilena transnacional como memoria colectiva (o memoria social como lo describiría Paul Connerton, 1989). "Las personas reconocemos y reconstruimos las imágenes de los eventos pasados cuando éstos forman parte de los 
pensamientos compartidos del grupo con el que estamos en estrecho contacto" (Connerton, 1989.).

Es así -siguiendo con Ramos- que la representación simbólica de la chilenidad por parte de los migrantes transnacionales -como los que se mencionaron anteriormente (misas a la chilena, peñas, conmemoración del 11 de septiembre, celebración de las fiestas patrias, etc.)- es una forma de evocar a la memoria, con la persistencia de las imágenes y conocimientos que ellos tienen de su pasado, es la comunicación de la chilenidad. Esta representación simbólica sería a través de prácticas más o menos rituales e incorporadas como hábitos en nuestras acciones cotidianas. En otras palabras, se toman imágenes del pasado, se evocan memorias, recuerdos, para representarlo simbólicamente a través de las distintas prácticas sociales que se llevan a cabo con y dentro de la comunidad chilena en Vancouver, aspectos tan sencillos como el mantener el idioma (incluso con aquellos nacidos en dicha ciudad), el "guitarrear" y cantar música chilena mientras se está en una reunión social, entre otros aspectos de la vida cotidiana que permitía el revivir y revitalizar la identidad chilena en un país ajeno. Este proceso de recordar se aplica de manera más específica luego del retorno a Chile y posteriormente el retorno a Vancouver, ya que el recuerdo que se evoca es de algo que ya no es existente para los exiliados, el Chile de la Unidad Popular, de una sociedad más comunitaria, empoderada políticamente, con compromisos sociales, todos estos que no vieron reflejados en el Chile actual.

Ellos están insertos en una sociedad canadiense, en donde deben adaptarse a la forma de vida de dicho país, tanto social, económica y políticamente, pero que dentro de su cotidianeidad persisten estas prácticas sociales que evocan de la identidad chilena. De esta manera este país permite recrear las prácticas sociales y culturales de los inmigrantes viviendo allá, formando de esta manera los espacios sociales transnacionales que se habían mencionado anteriormente.

Dado esto, la memoria funciona no tan solo como una práctica individual del recuerdo, si no que como una práctica social para recrear estos recuerdos y costumbres, estos simbolismos nacionales que identifican a este grupo social, a través del canto del himno nacional, el bailar cueca, el realizar peñas, misas a la chilena, comer empanadas, entre otras costumbres que es común entre los chilenos. 


\section{Conclusiones}

En resumidas palabras, para que pueda existir una vida transnacional en primer lugar deben haber migrantes (en este caso con la condición de migración forzada) residiendo en un mismo país en donde puedan representar y reproducir su identidad esencialista. Para que esto pueda suceder es que se tiene que evocar a la memoria (individual y colectiva), a las imágenes de lo que se recordaba que se hacía y estas imágenes son las que se representarán simbólicamente en el país de acogida, estos símbolos son los cuales representan su(s) identidad(es) en un espacio social transnacional, esto también a través de las redes fronterizas y transfronterizas que se genera con el país de origen y dentro del de acogida.

La existencia de una vida transnacional trae consigo la redefinición de identidades, ya sean estas identidades nacionales, políticas, culturales, sociales, etc. A su vez, es la identidad misma -tanto la esencialista como las que se fueron generando a posteriori (como la afirmativa y por oposición)- la que permite la existencia de una vida transnacional, es el deseo de querer "ser y pertenecer".

Según esto, se podría afirmar que la identidad tiene un carácter dinámico, la cual se va modificando según los distintos factores mencionados, en donde los contextos socioculturales, políticos, económicos, entre otros, afectan en las redefiniciones que las personas asignan a su identidad. Así mismo, el debate entre identidad e identidades comienza a tomar más fuerza, sobre todo cuando es concerniente a una investigación que habla sobre identidades nacionales, ya que una nación nunca será homogénea, sino que lo que caracteriza a cada nación, pueblo, comunidad, etc., son las heterogeneidades y las subjetividades de cada individuo, en donde claramente buscarán y reproducirán en conjunto las tradiciones y costumbres que tienen en común. En otras palabras, todo proceso de migración forzada de grandes masas generará una redefinición identitaria, la cual se irá reproduciendo a través de las comunidades transnacionales que se vayan generando en los lugares de residencia.

En este contexto, se evidencia además la relevancia tanto política como social y cultural por parte de la sociedad que acoge a los refugiados, ya que es ésta la que permite generar y mantener la vida transnacional.

La historia, la memoria y las experiencias vividas por los refugiados chilenos son las que irán moldeando la(s) identidad(es), ya que cada individuo tiene una historia distinta, hay quienes de los que llegaron a Canadá eran militantes políticos, por lo cual lo 
más probable es que será su identidad política lo que los vayan definiendo, llegaron ferroviarios, músicos, dueñas de casa, estudiantes (de liceo y universitarios), representantes de distintas etnias, todo esto incidiendo de manera directa a la redefinición de su identidad individual, pero a la vez, en conjunto, irán construyendo si identidad colectiva, reproduciendo las costumbres y tradiciones que consideren sean más pertinentes de mantener, reproducir o incluso modificar algunas de ellas.

Además, se destaca la necesidad desde los estudios de la antropología contemporánea de realizar este tipo de investigaciones, ya que abarca una gran cantidad de temas pertinentes como los estudios sobre identidad y transnacionalismo. Sin embargo, se destaca mayormente que el presente artículo responde a la necesidad de realizar estudios desde Chile para aquellos que se encuentran fuera del país de forma involuntaria, aquellos olvidados por el Estado. Muchos estudios se han hecho sobre el exilio y retorno de los chilenos, pero los estudios sobre transnacionalismo y, sobre todo, de identidad de los exiliados es un tema que debiera ser mejor explotado por los cientistas sociales, en específico de antropólogos.

\section{Referencias}

Aguirre, C. (2011). Something Fierce. Memoirs of a revolutionary daughter. Vancouver/Toronto/Berkeley: Douglas \& McIntyre publishers Inc.

Bauman, Z. (2000). Modernidad líquida. México D.F.; México: Fondo de Cultura Económica.

Beuchot, M. (2005). Hermenéutica, analogía, ícono y símbolo. En B. Solares y M. C. Valverde (eds.), Sym-bolon: Ensayos sobre cultura, religión y arte (pp. 75-88). México: Instituto de Investigaciones Filológicas, Universidad Nacional Autónoma de México.

Bolzman, C. (1993). Exilio, familia y juventud. En F. Montupil y J. Barudy (dir.), Exilio, derechos humanos y democracia. El exilio chileno en Europa (pp. 45-51). Santiago, Chile: Coordinación Europea de Comités Pro-retorno.

Connerton, P. (1989). How societies Remember. Cambridge: Cambridge University Press. 
Cuevas, H. (2008). La Cuestión de la identidad Chilena. En Instituto de Investigación en Ciencias Sociales, Chile 2008: Percepciones y aptitudes sociales (pp. 133-144). Santiago, Chile: Universidad Diego Portales.

Espinoza, A. y Buchanan-Arvay, M. (2004). Reconstruyendo identidades políticas: las narrativas post-dictadura de chilenos en el exilio. Reeditado del Journal of Constructivism in the Human Sciences, VA 9 (1), 91- 110.

Glick Schiller, N.; Basch, L. y Szanton Blanc, C. (1995). From Inmigrant to Transmigrant: theorizing transnational migration. Anthropological Quarterly, 68 (I), 48-63.

Grimson, A. (2010). Culture and Identity: two different notions. Social Identities, 16 (1), 6379.

Hall, S. (1993). Cultural Identity and Diaspora. En P. Williams y L. Chrisman (eds), Colonial Discourse and Post-colonial Theory: a Reader (pp. 222-237). Londres, Inglaterra: Harvester Wheatsheaf.

Handlin, O. (1973 [1951]). The uprooted, ed. Boston, Estados Unidos: Little Brown.

Lira, E. (2010). Memoria y Convivencia Democrática: Políticas de Olvido y Memoria. Santiago, Chile: FLACSO.

Ministerio de Justicia y Derechos Humanos de la Nación Argentina. (2006). Consecuencias actuales del terrorismo de Estado en la salud mental y Derechos Humanos. Cuadernillo orientativo dirigido a profesionales de la salud mental. Secretaría de Derechos Humanos del Ministerio de Justicia y Derechos Humanos de la Nación. BuenosAires, Argentina: Secretaría de Derechos Humanos del Ministerio de Justicia y Derechos Humanos de la Nación.

Moraes, N. (2007). Identidad Transnacional, Diáspora/s y Nación: Una reflexión a partir del estudio de la Migración Uruguaya en España. En D. Mato, A. Maldonado Fermín, Cultura y Transformaciones sociales en tiempos de globalización. Perspectivas Latinoamericanas (pp. 181-197). Buenos Aires, Argentina: Consejo Latinoamericano de Ciencias Sociales CLACSO.

Norambuena, C. (2000). Exilio y retorno. Chile. 1973-1994. En M. Garcés y P. Milo (Eds.), Memoria para un nuevo siglo. Chile, miradas a la segunda mitad del siglo XX (pp. 173187). Santiago, Chile: LOM Ediciones. 
Odgers-Ortiz, O. (2005). Migración, identidad y religión: aproximaciones al estudio del papel de la práctica religiosa en la redefinición identitaria de los migrantes mexicanos. Amèrique Latine Histoire et Mèmoire: Le Cahiers ALHIM 7.

Ramos, A. (2011). Perspectivas antropológicas sobre la memoria en contextos de diversidad y desigualdad. Revista Alteridades, 21 (42), 131-148.

Rebolledo, L. (2012). Exilios y Retornos Chilenos. Revista Anales, 3, 175-143.

Rettig, R., Castillo, J., Cea, J., Jiménez, M., Martin, R., Novoa, L., Vial, G., y Zalaquett, J. (1993). Informe de la Comisión Nacional de Verdad y Reconciliación Vol. 1. Santiago, Chile: Andros Impresores.

Ribeiro, L. (2001). Post-imperialismo: cultura y política en el mundo contemporáneo. Barcelona, España: Gedisa.

Santana, D. (2010). [Revisión del libro] Espacios y transnacionalismo. Cuadernos de geografía, de Hiernaux, D. y Zárate, M. (eds). Revista Colombiana de Geografía, 19, 187-190.

Sutcliffe, B. (1998). Nacido en otra parte. Un ensayo sobre la migración internacional, el desarrollo y la equidad. Bilbao, España: Hegoa.

Takaki, R. (1993). A different mirror: A history of multicultural America. Boston, Estados Unidos: Little Brown.

Tavernelli, R. (2011). El enfoque transnacional de las migraciones y el desafío de un análisis integral que tome la percepción de los nativos como parte del proceso. Buenos Aires, Argentina: Consejo Latinoamericano de Ciencias Sociales CLACSO.

Velasco, J. (2009). Transnacionalismo migratorio y ciudadanía en mutación. Claves de razón práctica, 197, 32-41.

Vono de Vilhena, D. (2006). Vinculación de los emigrados latinoamericanos y caribeños con su país de origen: transnacionalismo y políticas públicas. Serie Población y Desarrollo, 71. Santiago, Chile: CEPAL. 